\title{
The effect of $100 \%$ oxygen on tidal breathing parameters in preschool children
}

\author{
To the Editor:
}

The multiple-breath nitrogen washout $\left(\mathrm{MBN}_{2} \mathrm{~W}\right)$ test assesses ventilation distribution by determining the number of functional residual capacity (FRC) lung turnovers required for tidal breathing of $100 \%$ oxygen to wash out resident nitrogen from the lungs [1]. In particular, the test has gained significant interest as a tool for monitoring disease progression and prognosis in children with lung disease, with a specific focus on cystic fibrosis (CF) due to its ability to discriminate between health and disease [2]. The use of 100\% oxygen has become the preferred choice of inert gas in older children and adults. However, as discussed in the European Respiratory Society/American Thoracic Society consensus statement, there are disadvantages and unknowns as to how patient age, sedation and sleep state may interact with $100 \%$ oxygen to alter breathing patterns [3]. It is known that $100 \%$ oxygen alters breathing patterns in infants $[4,5]$ and therefore this approach is not recommended in this age group; however, it is assumed that the effect of $100 \%$ oxygen on respiration is diminished beyond infancy [3], with no reported impact of $100 \%$ oxygen on breathing parameters in school-aged children [6]. It remains unknown whether hyperoxia affects tidal breathing in young children, as there are no published studies in this age range. This study aimed to determine whether breathing $100 \%$ oxygen altered tidal breathing parameters in healthy young children and young children with CF.

$\mathrm{MBN}_{2} \mathrm{~W}$ tests were conducted in children with $\mathrm{CF}$ who were enrolled in the Australian Respiratory Early Surveillance Team for CF (AREST CF) surveillance programme and healthy children recruited from the community aged 3 to 6 years. Tests were performed (Exhalyzer D, Eco Medics AG, Duernten, Switzerland) according to international standards by using Spiroware software (version 3.1.8) [3]. Children performed at least $1 \mathrm{~min}$ of tidal breathing in room air (minimum of 20 tidal breaths) prior to breathing $100 \%$ oxygen as part of the $\mathrm{MBN}_{2} \mathrm{~W}$ test through a mouthpiece and with a noseclip on.

Tidal breathing parameters including tidal volume $(V \mathrm{~T})$, respiratory rate $(\mathrm{RR})$, minute ventilation $\left(V^{\prime} \mathrm{E}\right)$, mean tidal expiratory flow (MTEF) and mean tidal inspiratory flow (MTIF) were compared for air exposure and $100 \%$ oxygen exposure from the first $\mathrm{MBN}_{2} \mathrm{~W}$ trial, as this was the first exposure to oxygen and priming effects of oxygen exposure were shown in infants [4]. Results from subsequent trials were also available for comparisons. The variability of tidal breathing within each test was measured by calculating the coefficient of variation of $V \mathrm{~T}\left(\mathrm{CV}_{\mathrm{VT}}\right)$. Small breaths of $<3 \mathrm{~mL} \cdot \mathrm{kg}^{-1}$ were excluded [7]. Paired t-tests that compared tidal breathing parameters within children were performed by using SPSS Version 23 software (IBM SPSS Statistics, 2015) and the data reported as mean \pm SD.

$\mathrm{MBN}_{2} \mathrm{~W}$ data were collected from 43 children (15 healthy, 28 with CF) with a mean (range) age of 5.2 years (healthy 5.4 (3.7-6.6) years; CF $5.2(3.0-6.9)$ years; $\mathrm{p}=0.49)$. Of the 15 healthy children, nine had not performed $\mathrm{MBN}_{2} \mathrm{~W}$ before (60\%), whereas for children with CF only $21 \%(6 / 28)$ were $\mathrm{MBW}$-naïve. There were no significant differences in height (healthy $110.6 \pm 7.7 \mathrm{~cm}$; CF $110.1 \pm 8.5 \mathrm{~cm} ; \mathrm{p}=0.85$ ) and weight (healthy $19.7 \pm 4.7 \mathrm{~kg}$; CF $19.6 \pm 3.6 \mathrm{~kg} ; \mathrm{p}=0.90$ ) between healthy children and those with CF. FRC was not different between groups (healthy $0.90 \pm 0.16$; CF $0.88 \pm 0.21 ; \mathrm{p}=0.71$ ), but lung clearance index (LCI) was higher in children with CF than in healthy children (healthy 6.68 \pm 0.46 ; CF 8.12 \pm 1.56 ; $\mathrm{p}=0.001$ ). Breath number was higher ( $\sim 5$ breaths) when breathing $100 \%$ oxygen, due to the longer duration of nitrogen washout in children with $\mathrm{CF}$.

Mean VT was $4.8 \%$ or $13.3 \mathrm{~mL}$ lower during tidal breathing of $100 \%$ oxygen than with room air (table 1 ). This decrease in $V \mathrm{~T}$ was driven by a statistically significant $7 \%$ decrease in the $V \mathrm{~T}$ of healthy children upon breathing $100 \%$ oxygen $(\mathrm{p}=0.04)$. 10 of the 15 healthy children decreased their $V \mathrm{~T}$, with three children

@ERSpublications

Multiple breath nitrogen washout does not cause physiologically relevant breathing changes in preschool children http://ow.ly/xv9B30a0c7L

Cite this article as: Foong RE, Harper AJ, Hall GL, et al. The effect of 100\% oxygen on tidal breathing parameters in preschool children. Eur Respir J 2017; 49: 1601959 [https://doi.org/10.1183/13993003.019592016]. 
TABLE 1 Differences in tidal breathing parameters after breathing 100\% oxygen.

\begin{tabular}{|c|c|c|c|c|}
\hline & \multirow[t]{2}{*}{ Air } & \multirow[t]{2}{*}{$100 \%$ oxygen } & \multicolumn{2}{|c|}{ Difference ( $100 \%$ oxygen - air) } \\
\hline & & & Mean $(95 \% \mathrm{CI})$ & $\%$ \\
\hline \multicolumn{5}{|l|}{ All subjects ( $n=43)$} \\
\hline Breath number & $28.6 \pm 7.6$ & $33.6 \pm 9.9$ & $5.1(1.4 ; 8.7)^{\#}$ & 17 \\
\hline$V_{\top} \mathrm{mL}$ & $276.5 \pm 58.3$ & $263.3 \pm 53.8$ & $-13.2(-1.1 ;-25.3)^{\#}$ & -4.8 \\
\hline $\mathrm{CV}_{\mathrm{VT}} \%$ & $29.5 \pm 11.1$ & $28.8 \pm 9.8$ & $-0.6(2.2 ;-3.4)$ & -2.0 \\
\hline $\mathrm{RR} \min ^{-1}$ & $24.8 \pm 7.3$ & $24.0 \pm 7.4$ & $-0.9(-0.4 ;-2.1)$ & -3.6 \\
\hline$V^{\prime} \mathrm{E} \mathrm{mL} \cdot \mathrm{min}^{-1}$ & $6449.1 \pm 1370.6$ & $5913.5 \pm 1020.1$ & $-535.6(-234.7 ;-836.5)^{+}$ & -8.3 \\
\hline MTEF $\mathrm{mL} \cdot \mathrm{s}^{-1}$ & $196.5 \pm 47.8$ & $179.9 \pm 33.9$ & $-16.6(-7.7 ;-25.5)^{+}$ & -8.4 \\
\hline $\mathrm{MTIF} \mathrm{mL} \cdot \mathrm{s}^{-1}$ & $245.8 \pm 45.9$ & $230.2 \pm 37.3$ & $-15.6(-7.0 ;-24.2)^{+}$ & -6.3 \\
\hline $\mathrm{CO}_{2}$ emitted $\mathrm{mL}$ & $9.2 \pm 2.4$ & $8.7 \pm 2.3$ & $0.5(1.0 ; 0.1)^{\#}$ & 5.4 \\
\hline \multicolumn{5}{|c|}{ Healthy control subjects ( $n=15$ ) } \\
\hline Breath number & $27.5 \pm 7.5$ & $31.3 \pm 7.1$ & $3.7(1.4 ;-1.6)$ & 13.5 \\
\hline$V_{T} \mathrm{~mL}$ & $284.8 \pm 65.2$ & $263.5 \pm 46.2$ & $-21.2(-1.0 ;-41.5)^{\#}$ & -7.4 \\
\hline $\mathrm{CV}_{\mathrm{VT}} \%$ & $28.1 \pm 12.2$ & $26.8 \pm 11.2$ & $-1.4(4.1 ;-6.9)$ & -5.0 \\
\hline $\mathrm{RR} \min ^{-1}$ & $22.5 \pm 4.9$ & $22.0 \pm 6.2$ & $-0.5(1.6 ;-2.6)$ & -2.2 \\
\hline$V^{\prime} \mathrm{E} \mathrm{mL} \cdot \mathrm{min}^{-1}$ & $6073.4 \pm 1258.1$ & $5563.6 \pm 962.1$ & $-509.8(-14.6 ;-1005.0)^{\#}$ & -8.4 \\
\hline MTEF $\mathrm{mL} \cdot \mathrm{s}^{-1}$ & $191.7 \pm 45.2$ & $168.5 \pm 29.0$ & $-23.2(-9.5 ;-36.8)^{9}$ & -12.1 \\
\hline MTIF $\mathrm{mL} \cdot \mathrm{s}^{-1}$ & $236.1 \pm 51.5$ & $215.5 \pm 37.0$ & $-20.6(-7.2 ;-34.1)^{\pi}$ & -8.7 \\
\hline $\mathrm{CO}_{2}$ emitted $\mathrm{mL}$ & $9.3 \pm 2.6$ & $8.6 \pm 2.0$ & $0.4(1.3 ; 0.2)$ & 7.5 \\
\hline \multicolumn{5}{|c|}{ Subjects with cystic fibrosis ( $n=28$ ) } \\
\hline Breath number & $29.1 \pm 7.7$ & $34.9 \pm 11.1$ & $5.8(10.9 ; 0.7)^{\#}$ & 13.5 \\
\hline$V_{T} \mathrm{~mL}$ & $272.1 \pm 55.0$ & $263.2 \pm 58.3$ & $-8.9(6.9 ;-24.6)$ & -3.3 \\
\hline $\mathrm{CV}_{\mathrm{VT}} \%$ & $30.2 \pm 10.5$ & $29.9 \pm 9.0$ & $-0.2(3.2 ;-3.6)$ & -0.7 \\
\hline $\mathrm{RR} \min ^{-1}$ & $26.1 \pm 8.1$ & $25.0 \pm 7.8$ & $-1.0(0.5 ;-2.6)$ & -3.8 \\
\hline$V^{\prime} \mathrm{E} \mathrm{mL} \cdot \mathrm{min}^{-1}$ & $6650.4 \pm 1407.4$ & $6101.0 \pm 1017.1$ & $-549.4(-147.9 ;-950.9)^{9}$ & -8.3 \\
\hline MTEF $\mathrm{mL} \cdot \mathrm{s}^{-1}$ & $199.0 \pm 49.8$ & $186.0 \pm 35.2$ & $-13.1(-1.0 ;-25.1)^{\#}$ & -6.6 \\
\hline $\mathrm{MTIF} \mathrm{mL} \cdot \mathrm{s}^{-1}$ & $251.0 \pm 42.8$ & $238.1 \pm 35.6$ & $-12.9(-1.4 ;-24.5)^{\#}$ & -5.1 \\
\hline $\mathrm{CO}_{2}$ emitted $\mathrm{mL}$ & $9.1 \pm 2.3$ & $8.7 \pm 2.5$ & $0.7(1.3 ; 0.1)^{\#}$ & 7.7 \\
\hline
\end{tabular}

Data are presented as mean $\pm \mathrm{SD}$, unless otherwise stated. Bold indicates statistically significant values. Between measurement comparisons of tidal volume $\left(V_{T}\right)$, coefficient variation of $V_{T}\left(C V_{V T}\right)$, respiratory rate $(R R)$, minute ventilation ( $V^{\prime} E$ ), mean tidal expiratory flow (MTEF) and mean tidal inspiratory flow (MTIF). ${ }^{\#}: p<0.05 ;$ १: $p<0.01$; and ${ }^{+}: p=0.001$.

exhibiting a decrease in $V \mathrm{~T}$ of more than $20 \%$. The $V \mathrm{~T}$ during $100 \%$ oxygen breathing in children with $\mathrm{CF}$ did not significantly change from that in room air (table 1). The difference in $V \mathrm{~T}$ for room air to $100 \%$ oxygen was only present for the first trial, and no difference was observed for subsequent trials. Variability of $V \mathrm{~T}$ as determined by $\mathrm{CV}_{\mathrm{VT}}$ was not different for room air and $100 \%$ oxygen in any $\mathrm{MBN}_{2} \mathrm{~W}$ trial in either group.

Respiratory rate was unchanged during $100 \%$ oxygen exposure $(\mathrm{p}=0.16)$ (table 1$)$, however $V^{\prime} \mathrm{E}$ was significantly decreased $(\mathrm{p}=0.001)$ by $8 \%$ in both healthy children $(\mathrm{p}=0.04)$ and children with $\mathrm{CF}(\mathrm{p}=0.01)$. MTEF and MTIF were significantly lower during $100 \%$ oxygen exposure in healthy children $(\mathrm{p}<0.005)$ and children with CF ( $\mathrm{p}=0.03$ ) than in room air. Two healthy children (aged 5.9 and 5.3 years) and two children with CF (aged 3.4 and 4.3 years) had a reduction in MTEF of more than $60 \mathrm{~mL} \cdot \mathrm{s}^{-1}$ (table 1), when breathing $100 \%$ oxygen compared with room air. $V^{\prime}$ E, MTEF and MTIF remained lower for $100 \%$ oxygen than for room air in subsequent trials.

The data shows that tidal breathing of $100 \%$ oxygen significantly altered $V$ T, $V^{\prime}$ E, MTEF and MTIF in young children. Decreased VT with 100\% oxygen exposure was observed in healthy children but not those with CF. However, while the decrease in VT was statistically significant, the mean decrease was not more than $10 \%$ of the $V \mathrm{~T}$, which is the cut-off thought to be physiologically relevant. This postulated $10 \%$ cut-off was chosen as simulated lung volumes in children of 3-8 years using a lung model resulted in a $10 \%$ variation from known values $[6,8]$. Six (of 43) children had a change in VT value that exceeded $10 \%$, however there was no obvious effect of age or disease status in these individuals, and it is likely that the mean change in tidal breathing parameters was driven by a small number of individual children. There was no significant difference in the $\% \mathrm{CV}_{\mathrm{VT}}$ value between room air and $100 \%$ oxygen, which suggests that variation in tidal breathing pattern was not a contributing factor to the change in tidal breathing parameters.

Studies of the effects of $\mathrm{MBN}_{2} \mathrm{~W}$ in CF have been conducted in infants, including use of healthy infants as controls [4,5]. Singer et al. [4] showed a decrease in $V_{\mathrm{T}}$ value of $8.7 \%, 11 \%$ in $V^{\prime} \mathrm{E}$ and $14 \%$ in MTEF, 
whereas our study showed a decrease in $V \mathrm{~T}$ value of $4.8 \%, 8.3 \%$ in $V^{\prime} \mathrm{E}$ and $8.4 \%$ in MTEF. Differences between CF and healthy infants were not compared although the VT decrease in CF was double that of the healthy infants $(6.7 \mathrm{~mL}$ versus $2.7 \mathrm{~mL})$. Similar to our study, the authors reported heterogeneous responses independent of age and disease. More recently, Jost et al. [6] compared changes in tidal breathing following $\mathrm{MBN}_{2} \mathrm{~W}$ in healthy term-born and former preterm school-aged children (6-9 years), showing a small 3.5\% decrease in $V \mathrm{~T}$. While the preterm children recorded a significantly larger decrease in $V \mathrm{~T}$ value $(8 \%)$ than did healthy children $(0.7 \%)$ the study concluded that $100 \%$ oxygen had a minimal effect on tidal breathing.

A limitation of this study was that tidal breathing of room air was always performed prior to exposure to $100 \%$ oxygen, thus we cannot exclude an order effect. In particular, an order effect may have contributed to the higher $V \mathrm{~T}$ value in healthy children since these children were recruited from the community and, unlike the children with CF, had no prior experience of performing lung function tests in a clinical setting. Children unfamiliar with the test may have had an initial artificial increase in VT value and, once settled into the test, reduced their VT during the $100 \% \mathrm{O}_{2}$ exposure. Changes in VT influence LCI and FRC in infants [9], and unfortunately this study was not appropriately designed to test if LCI and FRC are altered by changes in breathing pattern in preschool children.

In summary, while changes in tidal breathing parameters were observed following breathing 100\% oxygen, there is no evidence to suggest that these changes are physiologically relevant across the preschool age group. Further studies should randomly alter the order of room air and 100\% oxygen exposure. Our data do not provide conclusive evidence that $\mathrm{MBN}_{2} \mathrm{~W}$ test should not be performed in preschool children.

Rachel E. Foong ${ }^{1,2}$, Alana J. Harper ${ }^{1,2}$, Graham L. Hall ${ }^{1,2,3}$ and Kathryn A. Ramsey ${ }^{1,2,4}$ on behalf of AREST CF

${ }^{1}$ Telethon Kids Institute, Perth, Australia. ${ }^{2}$ Centre for Child Health Research, University of Western Australia, Perth, Australia. ${ }^{3}$ School of Physiotherapy and Exercise Science, Curtin University, Perth, Australia. ${ }^{4}$ Cystic Fibrosis Research and Treatment Centre, University of North Carolina at Chapel Hill, Chapel Hill, NC, USA.

Correspondence: Rachel E. Foong, Telethon Kids Institute, 100 Roberts Roads, Subiaco 6008, Western Australia. E-mail: Rachel.Foong@telethonkids.org.au

Received: Oct 062016 | Accepted after revision: March 052017

Support statement: This work was supported by the Cystic Fibrosis Foundation (Hall14AO). G.L. Hall and K.A. Ramsey are supported by National Health and Medical Research Council Fellowships (APP102550 and APP1088389, respectively). Funding information for this article has been deposited with the Crossref Funder Registry.

Conflict of interest: None declared.

Acknowledgements: We would like to acknowledge Caroline Gallagher and Jasmine Grdosic (both from the Telethon Kids Institute, Perth, Australia) for assistance with patient recruitment and study measurements.

\section{References}

1 Robinson PD, Goldman MD, Gustafsson PM. Inert gas washout: theoretical background and clinical utility in respiratory disease. Respiration 2009; 78: 339-355.

2 Subbarao P, Milla C, Aurora P, et al. Multiple-breath washout as a lung function test in cystic fibrosis. A Cystic Fibrosis Foundation Workshop Report. Ann Am Thorac Soc 2015; 12: 932-939.

3 Robinson PD, Latzin P, Verbanck S, et al. Consensus statement for inert gas washout measurement using multipleand single- breath tests. Eur Respir J 2013; 41: 507-522.

4 Singer F, Yammine S, Schmidt A, et al. Ventilatory response to nitrogen multiple-breath washout in infants. Pediatr Pulmonol 2014; 49: 342-347.

5 Schibler A, Schneider M, Frey U, et al. Moment ratio analysis of multiple breath nitrogen washout in infants with lung disease. Eur Respir J 2000; 15: 1094-1101.

6 Jost K, Lenherr N, Singer F, et al. Changes in breathing pattern upon 100\% oxygen in children at early school age. Respir Physiol Neurobiol 2016; 228: 9-15.

7 Jensen R, Stanojevic S, Klingel M, et al. A systematic approach to multiple breath nitrogen washout test quality. PLOS ONE 2016; 11: e0157523.

8 Schmidt A, Yammine S, Proietti E, et al. Validation of multiple-breath washout equipment for infants and young children. Pediatr Pulmonol 2015; 50: 607-614.

9 Schmalisch G, Wilitzki S, Bührer C, et al. The lung clearance index in young infants: impact of tidal volume and dead space. Physiol Meas 2015; 36: 1601-1613. 